\title{
POTENSI PERHELATAN BUDAYA CAP GO MEH SEBAGAI SALAH SATU DAYA TARIK WISATA DI INDONESIA (STUDI KASUS PERHELATAN BUDAYA CAP GO MEH DI KOTA SINGKAWANG)
}

\author{
Potential Cultural Events Cap Go Meh As One of the Travel Attractions \\ in Indonesia (Case Study of Cap Go Meh Cultural Event in Singkawang \\ City) \\ Merry $^{1)}$, Rianto ${ }^{2)}$ \\ ${ }^{1)}$ Program Studi Hospitality dan Pariwisata ,Universitas Bunda Mulia \\ ${ }^{2)}$ Program Studi Hospitality dan Pariwisata ,Universitas Bunda Mulia
}

Diterima 12 Januari 2020 / 16 Februari 2020

ABSTRACT

Cap Go Meh is a hereditary tradition from the Chinese ethnic in Indonesia which held on the 15th day of the first month of the Chinese New Year. This celebration varies in each place, one of which is in Singkawang City which was formed through the assimilation and acculturation of Chinese culture with local people in the Chinese village of Monterado centuries ago with the Tatung parade as the highlight. This research aims to see whether this cultural event can be a potential tourist attraction in Indonesia and whether it has an impact to Singkawang City.

This research conducted on Chinese New Year 2570 and Cap Go Meh 2019 in Singkawang City using qualitative descriptive research methods with primary data collection including in-depth interviews, field observations, and supported by secondary data of documents collection.

From the results of research on tourism businesses include hotels, restaurants, travel agents, rent cars, street vendors and retail stores, concluded Cap Go Meh in Singkawang City has potential as a tourist attraction in Indonesia especially cultural tourism which born from a tradition with a tolerance message of ethnic diversity in Singkawang City. The government also provides promotional support and continues to develop this cultural event in collaboration with regional organizations. Local people are also open to tourism activities and support directly and indirectly. The biggest positive impact is the economic growth for citizens, regional income and creation of employments for citizens. The negative impact is on the environment, namely the increases of waste caused by tourists and the price increases of hotel rooms and tour package that are too high which can burdensome tourists and decreasing interest in tourist visits to Singkawang City.

Keyword: Potential, Tourism, Event, Culture, Cap Go Meh, Tourist Attraction, Singkawang City, Qualitative, Dscriptive, Impact

\section{ABSTRAK}

Cap Go Meh merupakan tradisi turun temurun masyarakat etnis Tionghoa di Indonesia yang dilaksanakan pada hari ke 15 bulan pertama Tahun Baru Imlek. Perayaan ini berbeda-beda di setiap tempat, salah satunya di Kota Singkawang yang terbentuk melalui proses asimilasi dan akulturasi budaya orang China dengan masyarakat lokal di perkampungan China di Monterado berabad-abad yang lalu dengan pawai Tatung sebagai puncak perhelatannya. Penelitian ini bertujuan untuk melihat apakah perhelatan budaya ini dapat menjadi sebuah potensi daya tarik wisata di Indonesia serta apakah perhelatan budaya ini menimbulkan dampak pada Kota Singkawang.

Penelitian ini dilakukan pada Tahun Baru Imlek 2570 dan Cap Go Meh 2019 di Kota Singkawang menggunakan metode penelitian deksriptif kualitatif dengan teknik pengumpulan data primer meliputi wawancara mendalam, observasi lapangan, dan didukung oleh data sekunder pengumpulan dokumen.

*Korespondensi Penulis:

E-mail: rianto@bundamulia.ac.id 
Dari hasil penelitian terhadap usaha pariwisata meliputi akomodasi penginapan (hotel), restoran (rumah makan), agen perjalanan, sarana transportasi (rental mobil), pedagang kaki lima dan retail store, bahwa perhelatan budaya Cap Go Meh di Kota Singkawang ini memiliki potensi sebagai daya tarik wisata di Indonesia khususnya wisata budaya yang lahir dari sebuah tradisi dengan pesan toleransi keberagaman etnis di Kota Singkawang. Pemerintah juga ikut memberikan dukungan promosi dan terus mengembangkan perhelatan budaya ini dengan bekerjasama antar Organisasi Perangkat Daerah (OPD). Masyarakat lokal juga terbuka akan kegiatan pariwisata dan ikut mendukung secara langsung dan tidak langsung. Dampak positif yang paling besar adalah dampak terhadap pertumbuhan ekonomi masyarakat dan pendapatan asli daerah serta terciptanya lapangan kerja bagi masyarakat lokal. Adapun dampak negatif yang ditimbulkan adalah terhadap lingkungan yaitu bertambahnya sampah yang disebabkan wisatawan dan kenaikan harga kamar hotel dan paket perjalanan yang terlalu tinggi sehingga dapat berdampak pada kunjungan wisatawan ke Kota Singkawang.

Kata Kunci: Potensi, Pariwisata, Perhelatan, Budaya, Cap Go Meh, Daya Tarik Wisata, Kota Singkawang, Kualitatif, Deskriptif, Dampak

\section{PENDAHULUAN \\ Latar Belakang Masalah}

Sektor Pariwisata Indonesia semakin berkembang setiap tahun. Pemerintah bahkan menargetkan jumlah kunjungan wisatawan sebanyak 20 juta wisatawan mancanegara dan 275 wisatawan nusantara pada tahun 2020. Destinasi berdasarkan Kementerian Pariwisata dibedakan menjadi 4 yaitu destinasi berbasis alam, buatan, sejarah dan budaya. Salah satu jenis destinasi wisata yang berkembang dan menjadi daya tarik wisata di Indonesia adalah wisata budaya.

Indonesia memiliki 1331 kategori suku berdasarkan SP2010 dalam situs resmi Badan Pusat Statistik (BPS) yang meliputi kode untuk nama suku, nama lain (alias) suku, hingga sub suku. Banyaknya suku ini menjadikan Indonesia kaya akan wisata budaya yang unik dan beragam.

Perkembangan wisata budaya di Indonesia tidak hanya berkembang di Bali, tetapi juga di provinsi lainnya dengan otentitas dan keunikan masing-masing daerah yang dapat dilestarikan dan dikembangkan dengan baik sehingga dapat menjadi konsumsi wisata bagi wisatawan lokal dan mancanegara.

Pemerintah saat ini sangat menekankan sektor pariwisata, khususnya di daerah atau provinsi yang dahulu mengandalkan perekonomian pada sektor minyak, gas, dan memiliki potensi hutan yang besar seperti Pulau Kalimantan.
Pulau Kalimantan memiliki beranekaragam etnis seperti Dayak, Bugis, Banjar, Madura, Melayu, Tionghoa, dan sebagainya. Kalimantan tidak hanya kaya akan potensi hutan namun juga kebudayaan yang masih dijalankan oleh masyarakat lokal hingga saat ini, salah satunya di Kalimantan Barat.

Di Kalimantan Barat, ada sebuah prosesi budaya yang masih dilaksanakan turun temurun setiap tahun oleh masyarakat etnis Tionghoa, yakni budaya Cap Go Meh seperti di Kota Pontianak dan Kota Singkawang. Hal ini menjadi potensi pariwisata yang diharapkan dapat berdampak pada peningkatan pendapatan terhadap daerahdaerah di Kalimantan Barat khususnya Kota Singkawang.

Kota Singkawang berbatasan langsung dengan Kabupaten Sambas dan Kabupaten Bengkayang, atau $145 \mathrm{~km}$ arah Timur Laut dari Kota Pontianak, Ibu Kota Kalimantan Barat. Kota Singkawang atau dalam dialek peranakkan Tionghoa San Keuw Jeong atau dalam bahasa Mandarin 山口洋 shān (gunung) kóu (mulut) yáng (lautan) merupakan bentuk pemerintahan kota yang terbentuk pada 17 Oktober 2001 dan merupakan hasil pemekaran dari Kabupaten Bengkayang berdasarkan UU Nomor 12 Tahun 2001 Tentang Pembentukan Kota Singkawang.

Selain menjadi kota perdagangan, Kota Singkawang juga berpotensi untuk wisata budaya. Hal ini ditunjukkan dengan situs- 
situs warisan budaya seperti klenteng, rumah-rumah adat di Kota Singkawang yang masih mempertahankan desain tempo dulu. Kota Singkawang dijuluki sebagai Kota Seribu Klenteng dan Kota "Amoi”, sebutan untuk anak perempuan Tionghoa.

Berwisata ke Kota Singkawang tidak cukup dimanjakan oleh kekayaan budaya-nya saja, akan tetapi juga keindahan alamnya. Bahkan, salah satu hal yang paling bisa ditonjolkan adalah pluralisme budaya masyarakat-nya yang juga dapat menjadi daya tarik wisata di kota ini. Kota Singkawang khas dengan pluralitas budayanya yakni "Tidayu" (Tionghoa, Dayak, Melayu) yang telah lama hidup berdampingan dalam kehidupan bermasyarakat di Kota Singkawang.

Yang mana, masyarakat-nya sudah biasa hidup berdampingan sejak lama satu sama lain membawa dampak positif dan menjadikan Singkawang dinobatkan sebagai Kota Paling Toleran pada tahun 2018 dari 93 kota lainnya di Indonesia oleh Setara Institute, sebuah organisasi non government $(N G O)$ yang bertujuan untuk mengeliminasi intoleransi berbasis suku, agama, ras, dan status sosial.

Cara hidup bermasyarakat yang tenteram ini menjadikan Kota Singkawang mulai dikenal oleh wisatawan akan pluralitas budaya-nya yang unik. Salah satu budaya yang masih dilestarikan di Kota Singkawang adalah budaya Cap Go Meh dengan pawai Tatung sebagai salah satu atraksi yang menjadi daya tarik utama.

Dengan perayaan Cap Go Meh yang telah dilakukan, berdasarkan Dinas Pariwisata, Pemuda, dan Olahraga Kota Singkawang, pada tahun 2018 tercatat sebanyak 721.967 wisatawan yang berkunjung ke Kota Singkawang. Angka ini meningkat 10,70\% dari tahun 2017 yakni 652.184 wisatawan. Kota Singkawang selain memiliki potensi budaya, juga memiliki destinasi lainnya antara lain Pulau Sinka, Air Terjun Eria, Rindu Alam, Cagar Alam Raya Pasi, Batu Belimbing, Rumah Sejarah Marga Xie, Taman Bougenville, dan Pantai Pasir Panjang Indah.
Berdasarkan kegiatan yang dilakukan setiap tahun, diharapkan daya tarik wisata ini berdampak pada jumlah kunjungan wisatawan untuk mensukseskan target pencapaian 20 juta wisatawan mancanegara dan 275 juta wisatawan nusantara. Oleh karena itu, peneliti tertarik untuk meneliti "Potensi Perhelatan Budaya Cap Go Meh Sebagai Salah Satu Daya Tarik Wisata Di Indonesia (Studi Kasus Perhelatan Budaya Cap Go Meh Di Kota Singkawang)".

\section{Identifikasi Masalah}

Berdasarkan latar belakang masalah diatas, peneliti akan melakukan identifikasi masalah meliputi:

1. Masih terpeliharanya budaya Cap Go Meh di Kota Singkawang yang dirayakan secara turun temurun oleh masyarakat etnis Tionghoa di Indonesia khususnya di Kota Singkawang, Kalimantan Barat.

2. Sampai saat ini masyarakat Kota Singkawang sangat memegang teguh tradisi Cap Go Meh dengan melaksanakan tradisi ini setiap tahun dengan terpeliharanya klenteng-klenteng dan bangunan adat di Kota Singkawang.

3. Jumlah kunjungan wisatawan di Kota Singkawang pada tahun 2016 - 2018 . Pada tahun 2017 tercatat sebanyak 652.184 wisatawan dengan persentase peningkatan 26,64\% dari tahun 2016 yakni 514.989 wisatawan. Sedangkan pada tahun 2018 tercatat sebanyak 721.967 wisatawan dengan persentase peningkatan 10,70\% dari tahun 2017.

4. Tingakt pemenuhan dan harga industri akomodasi di Kota Singkawang saat perhelatan budaya Cap Go Meh

\section{Tujuan dan Manfaat Penelitian}

Tujuan penelitian ini adalah sebagai berikut

\section{Tujuan Penelitian}

Tujuan penelitian ini untuk mengetahui potensi apa saja yang timbul baik segi positif maupun negatif dalam pelaksanaan perhelatan Perhelatan Budaya Cap Go Meh dari segi pelaku 
industri pariwisata, pengunjung, masyarakat dan pemerintah Kabupaten Singkawang khususnya .

2. Manfaat penelitian

Manfaat penelitian ini untuk mengetahui apakah perhelatan budaya Cap Go Meh dapat di jadikan alternatif atrkasi yang menjadi kalender tahunan di Indonesia.

\section{Pariwisata dan Kepariwisataan}

Menurut Undang-Undang Nomor 10 Tahun 2009 Tentang Kepariwisataan, wisata merupakan kegiatan perjalanan yang dilakukan oleh seseorang atau sekelompok orang dengan mengunjungi sebuah destinasi dengan tujuan rekreasi, pengembangan pribadi, atau untuk mempelajari keunikan daya tarik wisata yang dikunjungi selama beberapa waktu (Pasal 1 Ayat 1).

Sedangkan pariwisata merupakan berbagai macam kegiatan wisata yang didukung berbagai fasilitas dan layanan yang disediakan oleh masyarakat, pengusaha, pemerintah, dan pemerintah daerah (Pasal 1 Ayat 3).

Definisi pariwisata menurut World Tourism Organization (UNWTO):

"tourism comprises the activities of persons traveling to and staying in places outside their usual environment for not more than one consecutive year for leisure, business and other purposes."

Bahwa pariwisata merupakan serangkaian aktivitas perjalanan yang dilakukan oleh individu atau sekelompok orang ke suatu tempat dan tinggal diluar kebiasaan lingkungannya selama tidak lebih dari satu tahun dengan tujuan berwisata, bisnis, dan tujuan lainnya.

\section{Dampak Pariwisata}

Dampak pariwisata dapat bersifat positif maupun negatif. Positif apabila kegiatan pariwisata memberikan manfaat bagi masyarakat dan pemerintah. Negatif apabila kegiatan pariwisata menimbulkan kerugian bagi masyarakat (lingkungan sosial budaya) serta lingkungan alam (ekologi).

1. Dampak Terhadap Ekonomi
Menurut Cohen dalam Pitana (2009:185), ada 8 dampak pariwisata terhadap sosial ekonomi masyarakat lokal, yaitu:

1. Penerimaan devisa;

2. Pendapatan masyarakat;

3. Kesempatan kerja;

4. Harga;

5. Distribusi manfaat/keuntungan;

6. Kepemilikan dan kontrol;

7. Pembangunan umum;

8. Pendapatan pemerintah.

2. Dampak Terhadap Lingkungan

Menurut Oka Yoeti dalam Muhammad Faiz (2017:23), beberapa dampak negatif yang dihasilkan pariwisata terhadap lingkungan, yaitu:

1. Pembuangan sampah sembarangan selain menyebabkan bau tidak sedap, juga membuat tanaman disekitarnya mati;

2. Pembuangan limbah hotel, restoran, dan rumah sakit yang merusak air sungai, danau, dan laut.

3. Kerusakan terumbu karang akibat pemboman oleh nelayan yang tidak lagi memiliki pantai untuk mencari ikan, karena pantai telah dikavling untuk membangun hotel dan restoran sehingga tidak ada lagi daya tarik pantai;

4. Perambahan hutan dimana-mana sehingga orang utan keluar dari habitatnya, langkanya burung cenderawasih yang mengakibatkan hilangnya daya tarik wisata alam; dan

5. Pengrusakan sumber-sumber hayati yang tidak terkendali, mengeksploitasi hutan bakau untuk dijadikan tambak udang.

Adapun diharapkan dalam setiap kegiatan pariwisata yang dilaksanakan, dampak negatif dapat diringankan sedemikian rupa agar dapat menjadi kegiatan pariwisata yang berkelanjutan (sustainable tourism).

Sustainable tourism adalah industri pariwisata yang mengupayakan keringanan pada dampak yang ditimbulkan terhadap lingkungan dan budaya lokal dapat 
membantu menghasilkan pendapatan, menciptakan lapangan kerja, dan juga konservasi terhadap ekosistem (Getaways dalam Ernawati, 2010:8).

Sustainable tourism juga dijelaskan oleh World Tourism Organization (WTO) dalam Ernawati (2010:8) sebagai kepariwisataan yang berfokus pada pengelolaan segala sumber dengan sedemikian rupa sehingga baik ekonomi, sosial, dan keindahan dapat terpenuhi; serta integritas budaya, ekologi, keanekaragaman hayati dan sistem pendukung lingkungan dapat terjaga dengan baik.

\section{Pariwisata Budaya}

Pariwisata budaya merupakan salah satu jenis pariwisata yang telah lama berkembang di Indonesia yang menjadikan budaya sebagai daya tarik utama dalam kegiatan kepariwisataan. Menurut International Council on Monuments and Sites (ICOMOS) (2012), pariwisata budaya merupakan kegiatan pariwisata yang meliputi semua pengalaman yang didapat oleh wisatawan di suatu tempat yang berbeda dari lingkungan tempat tinggal asalnya. Timothy dan Nyaupane dalam Oktaniza (2013:67) menyatakan bahwa pariwisata budaya (heritage tourism) biasanya terbangun dari budaya yang mengarah pada penggunaan masa lalu yang tangible dan intangible sebagai riset pariwisata yang diturunkan hingga sekarang seperti tarian, bahasa, musik, bangunan seperti monumen, museum, dan sebagainya.

\section{METODOLOGI PENELITIAN Desain Penelitian}

Peneliti menggunakan metode penelitian dengan desain penelitian kualitatif dengan menggunakan pendekatan studi kasus yang bertujuan untuk menelaah dan memahami sebuah fenomena yang terjadi dalam sebuah situasi sosial, misalnya dampak, perilaku, dan sebagainya.

Menurut Afrizal (2017:13), metode penelitian kualitatif merupakan metode penelitian ilmu-ilmu sosial yang mengumpulkan dan menganalisa data berupa katakata secara lisan ataupun tulisan, dan perbuatan-perbuatan manusia. Afrizal melanjutkan, dalam penelitian kualitatif, peneliti tidak berusaha menghitung atau mengkuantifikasikan data kualitatif yang telah diperoleh dan juga tidak menganalisis angka-angka. penelitian deskriptif kualitatif yang bertujuan untuk

meringkaskan sebuah fenomena dan realitas sosial yang ada di masyarakat mengenai potensi perhelatan budaya Cap Go Meh sebagai daya tarik wisata di Indonesia dan apakah ada dampak yang ditimbulkan.

\section{Teknik Pengumpulan Data}

1. Wawancara.

Adapun teknik wawancara yang dilakukan peneliti adalah wawancara terencana-tidak terstruktur. Wawancara terencana-tidak terstruktur adalah jenis wawancara dengan rencana yang telah disusun secara matang oleh peneliti, namun tidak menggunakan format dan urutan yang baku saat melakukan wawancara kepada informan (Muri Yusuf, 2017:377).

Wawancara dilakukan langsung di Kota Singkawang dan informan yang di wawancara ada 10 lapisan masyarakat.

\section{Observasi}

Tipe observasi yang dilakukan peneliti adalah participant observer dan observasi terkontrol (controlled observation). Participant observer merupakan bentuk observasi dimana peneliti secara teratur berpartisipasi dan terlibat dalam kegiatan atau fenomena yang diteliti. Peneliti menentukan dengan rinci mengenai apa yang diamati dari alokasi, penentuan waktu, dan pendekatan yang relevan dengan bagian yang akan diamati (Muri Yusuf, 2017:384). Peneliti dalam hal ini berpartisipasi sebagai pengamat (participant as observer) yang berfungsi sebagai pengamat (observer) dan sebagai 
subordinat dari kelompok dan diterima oleh kelompok selama waktu pengamatan kegiatan perhelatan budaya Cap Go Meh di Kota Singkawang.

\section{Populasi dan Sampel}

Dalam metode penelitian kualitatif, sampel disebut dengan informan penelitian. Informan penelitian merupakan orang yang memberikan informasi baik tentang dirinya ataupun orang lain mengenai suatu kejadian ataupun sesuatu hal kepada peneliti (Afrizal, 2017:139).

Tabel 1.

Informasi Penelitian

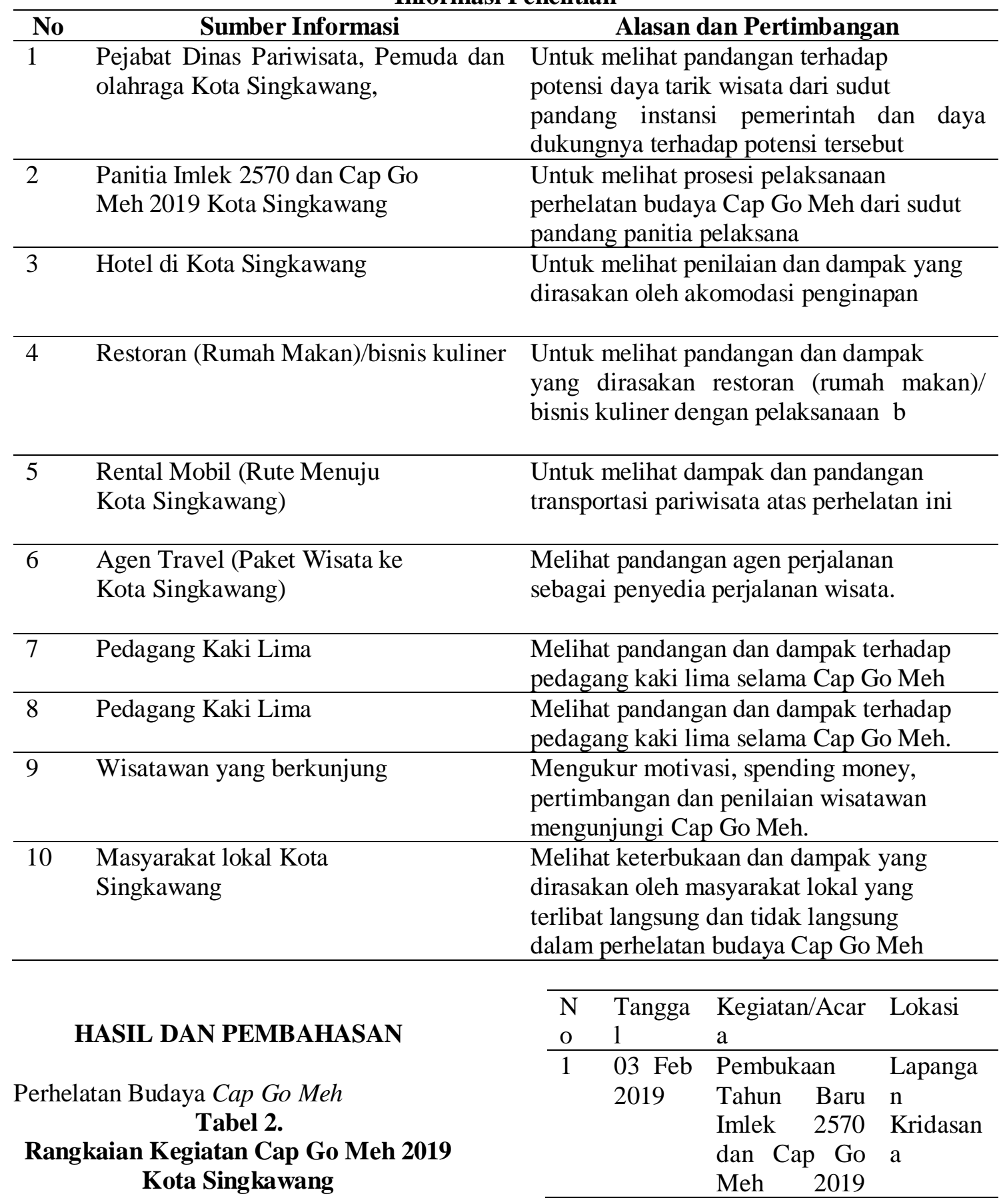




\begin{tabular}{|c|c|c|c|}
\hline & & $\begin{array}{l}\text { Kota } \\
\text { Singkawang } \\
\text { Lapangan } \\
\text { Kridasana }\end{array}$ & \\
\hline 2 & \multirow{2}{*}{$\begin{array}{l}03-20 \\
\text { Feb } \\
2019\end{array}$} & $\begin{array}{l}\text { Pentas } \\
\text { Festival Seni } \\
\text { dan Budaya }\end{array}$ & \multirow{6}{*}{$\begin{array}{l}\text { Lapanga } \\
\mathrm{n} \\
\text { Kridasan } \\
\mathrm{a}\end{array}$} \\
\hline 3 & & $\begin{array}{l}\text { Expo } \\
\text { (UMKM \& } \\
\text { Promosi } \\
\text { Produk / Jasa) }\end{array}$ & \\
\hline 4 & \multirow[t]{2}{*}{$\begin{array}{l}17 \mathrm{Feb} \\
19\end{array}$} & $\begin{array}{lr}\text { Prosesi } & \text { Ritual } \\
\text { Buka } & \text { Mata } \\
\text { Replika } & 12 \\
\text { Naga } & \text { Pekong } \\
\text { Pusat } & \text { Bumi } \\
\text { Raya } & \text { Kota } \\
\text { Singkawang }\end{array}$ & \\
\hline 5 & & $\begin{array}{l}\text { Festival Pawai } \\
\text { Lampion Kota } \\
\text { Singkawang }\end{array}$ & \\
\hline 6 & $\begin{array}{l}18 \text { Feb } \\
19\end{array}$ & $\begin{array}{lr}\text { Prosesi } & \text { Ritual } \\
\text { Sembahyang } \\
\text { Dewa } & \text { Langit } \\
\text { (Ket } \quad \text { Sam } \\
\text { Thoi) Kota } \\
\text { Singkawang }\end{array}$ & \\
\hline 7 & $\begin{array}{l}19 \text { Feb } \\
19\end{array}$ & $\begin{array}{l}\text { Ritual Tolak } \\
\text { Bala oleh Para } \\
\text { Rohaniawan / } \\
\text { Tatung Kota } \\
\text { Singkawang }\end{array}$ & \\
\hline 8 & $\begin{array}{l}18-19 \\
\text { Feb } 19\end{array}$ & $\begin{array}{l}\text { Stand Wisata } \\
\text { Kuliner }\end{array}$ & $\begin{array}{l}\text { J1. Kepol } \\
\text { Mahmud } \\
2\end{array}$ \\
\hline 9 & $\begin{array}{l}19 \mathrm{Feb} \\
19\end{array}$ & $\begin{array}{l}\text { Altar } \quad \& \\
\text { Lelang Kota } \\
\text { Singkawang }\end{array}$ & \\
\hline & & $\begin{array}{l}\text { Prosesi } \\
\text { Pembakaran }\end{array}$ & \\
\hline & & $\begin{array}{l}12 \text { Naga } \\
\text { Vihara } \\
\text { Buddhayana } \\
\text { Roban (Cai } \\
\text { Thong) }\end{array}$ & \\
\hline 10 & $\begin{array}{l}20 \mathrm{Feb} \\
19\end{array}$ & \begin{tabular}{l}
\multicolumn{2}{l}{ Penutupan } \\
Tahun Baru \\
Imlek 2570 \\
dan Cap Go \\
Meh 2019
\end{tabular} & $\begin{array}{l}\text { Lapanga } \\
\mathrm{n} \\
\text { Kridasan } \\
\mathrm{a}\end{array}$ \\
\hline
\end{tabular}

\section{Kota}

Singkawang

Sumber: Panitia Imlek 2570 dan Cap Go Meh 2019)

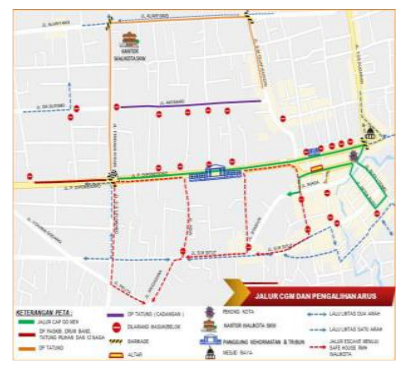

Gambar 1.

\section{Peta Peta Jalur Cap Go Meh 2019}

Peserta yang berpartisipasi dalam pawai dikategorikan menjadi beberapa jenis. Ada Tatung yang menggunakan tandu, Tatung tanpa tandu, Jelangkung, Barongsai, Naga, 麒麟 (qúlín) atau Kilin, dan sebagainya.

Pada tahun ini, jumlah peserta yang berpartisipasi dalam perhelatan budaya Cap Go Meh mengalami penurunan dibandingkan tahun lalu. Pada tahun 2018 jumlah peserta 1145 peserta, menurun 105 peserta menjadi 1040 di tahun 2019.

Selain pawai Tatung, terdapat pula kegiatan lelang barang-barang unik di altar.

Bapak Budiman mengatakan, altar merupakan tempat persemayaman Dewa Bumi, dan kegiatan lelang di altar dimaksudkan karena adanya kepercayaan bahwa barang-barang yang dilelang memiliki nilai lebih untuk keselamatan dan kesuksesan kepercayaan orang Tionghoa yang dijual dengan harga sangat tinggi.

Di depan area pelelangan di altar ini juga disediakan tempat duduk untuk tamu undangan dan penonton yang tiketnya dijual seharga Rp200.000 per kursi. Tiket tribun ini dapat dibeli melalui panitia pelaksana atau melalui agen perjalanan yang melayani paket wisata Cap Go Meh ke Kota Singkawang. Perhelatan budaya Cap Go Meh kemudian ditutup dengan prosesi bakar naga 
Versi Online:

https://journal.ubm.ac.id/index.php/hospitality-pariwisata

DOI : http://dx.doi.org/10.30813/.v6i1.2025

Hasil Penelitian
Jurnal Hopitality dan Pariwisata

Vol.6 (No. 1) : no. 1 - no 55. Th. 2020

ISSN: 2442- 5222

e-ISSN : 2655-8165 setelah pawai Tatung yang melambangkan berakhirnya Tahun Baru Imlek pada 19 Februari 2019 diiringi penutupan resmi pada 20 Februari 2019 yang ditutup dengan pidato oleh Ibu Tjhai Cui Mie, Walikota Singkawang.
Berikut adalah beberapa dokumentasi perhelatan budaya Cap Go Meh 2019:

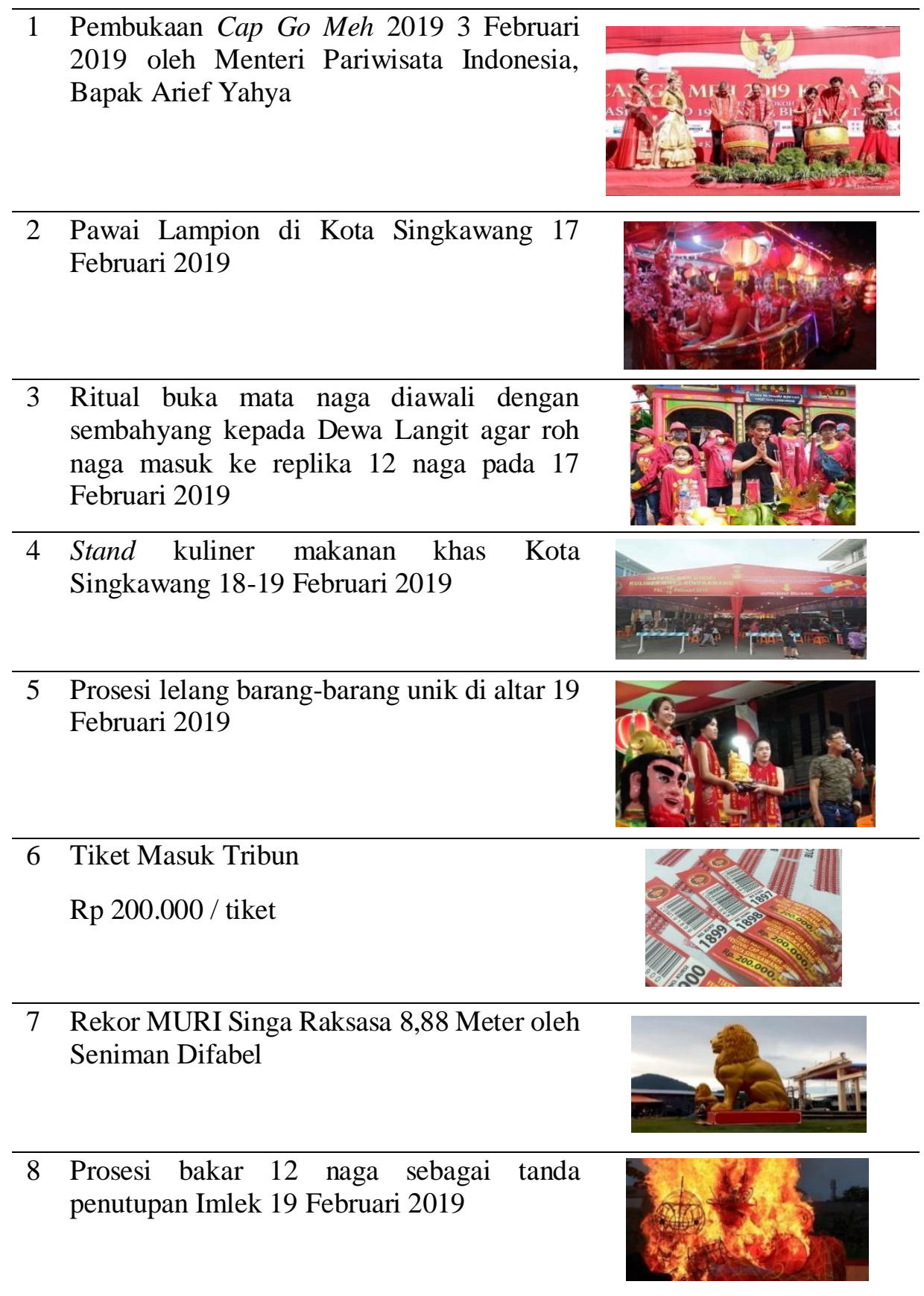


9 Penutupan Cap Go Meh 2019, oleh Walikota Kota Singkawang, Ibu Tjhai Cui Mie 20 Februari 2019

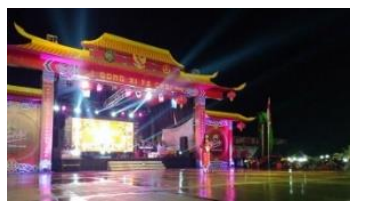

Sumber: Dokumentasi koleksi peneliti)

Perhelatan budaya Cap Go Meh di Kota Singkawang telah dijalankan turun temurun sejak lama oleh masyarakat Tionghoa di Kota Singkawang. Namun baru sejak tahun 2008, perhelatan budaya ini mulai membuka mata dunia.

Bapak Supardiyana, Kepala Bagian Pariwisata Dinas Pariwisata, Pemuda, dan Olahraga Kota Singkawang menilai bahwa tradisi Cap Go Meh ini dapat dikemas menjadi sebuah atraksi wisata budaya, sehingga pemerintah kota kemudian memoles dan mengemas perhelatan budaya ini agar menjadi daya tarik nusantara dan mancanegara. Pemerintah dan masyarakat bekerja sama dengan pemangku usaha untuk mengembangkan Cap Go Meh hingga menjadi tontonan tingkat dunia.

Bapak Supardiyana menambahkan, bahwa perkembangan Cap Go Meh tahun ke tahun semakin baik, memerlukan usaha dan dukungan dari banyak pihak seperti Kementerian Pariwisata, Satuan Kerja Perangkat Daerah (SKPD), tokoh-tokoh masyarakat Tionghoa, sampai dengan pemangku usaha di industri pariwisata.

Perkembangan Cap Go Meh setiap tahun yang semakin baik juga dilihat dari bentuk dukungan yang diberikan oleh Pemerintah Kota Singkawang, tidak hanya dari dukungan dana kepada kelompok masyarakat adat, namun Pemerintah Kota Singkawang pun turut mendukung acara ini dengan mengagendakan acara ini di Calendar of Event Kota Singkawang dan terus mempromosikan acara ini agar dikenal masyarakat luas.

"Kita pemerintah daerah, kota, provinsi, kementerian pusat juga memberikan alokasi dukungan baik dari bentuk promosi, alokasi dana yang diberikan kepada kelompok masyarakat adat, sehingga mereka juga ada dana yang diberikan. Dari kementerian juga tentunya dukungan promosi."

Hal ini ternyata juga senada dengan yang disampaikan oleh Bapak Budiman dari kacamata Panitia Imlek 2570 dan Cap Go Meh 2019 yang menyatakan mendapat dukungan positif dari pemerintah:

"Kita dapat bantuan APBD, udah beberapa tahun sudah dapat. Pemerintah juga sangat support. Tatung-Tatung ini juga disantuni dari APBD dan pihak swasta. Santunannya per orang 3 juta. Yang paling tinggi yang duduk parang sudah punya kekuatan tinggi. Yang jalan mengiringi juga dibayar 300ribu, tahun lalu 600ribu tahun ini menurun."

Meskipun mengalami penurunan jumlah santunan peserta pawai pada tahun 2019, namun Panitia Imlek 2570 dan Cap Go Meh 2019 mengaku sangat terbantukan oleh dukungan pemerintah kota. Sebab itu berarti dengan dana yang diberikan kepada peserta Tatung dan kelompok adat masyarakat yang menjalankan acara, ada apresiasi terhadap karya mereka.

Santunan yang diterima oleh peserta mulai dari Rp300.000 untuk Jelangkung dan Tatung tanpa tandu, sampai yang paling besar Rp3.000.000 untuk Tatung dengan tandu atau Rp3.600.000 untuk Naga. Peserta yang menerima santunan adalah peserta yang telah mendaftar pada tanggal 3 Januari - 3 Februari 2019 dan telah lulus verifikasi standar dari panitia.

\section{Pandangan Sektor Industri Akomodasi (Hotel) di Kota Singkawang}

Lama tinggal tamu hotel merupakan indikator penting untuk mengetahui ketertarikan wisatawan mengunjungi sebuah 
destinasi wisata. Tingkat hunian hotel juga berperan penting pada indikator kesuksesan sebuah hotel dalam menjual kamar, sebab semakin tinggi tingkat hunian kamar, semakin banyak jumlah kamar yang terjual. Semakin lama wisatawan tinggal di sebuah daerah, maka semakin tinggi spending money yang dikeluarkan. Semakin tinggi spending money wisatawan, maka akan berdampak positif pada pendapatan masyarakat dan daerah

Tabel 2.

Occupancy Hotel di Kota Singkawang Saat Cap Go Meh 2019

\begin{tabular}{|c|c|c|c|c|c|c|c|c|}
\hline \multirow[b]{2}{*}{ No } & \multirow{2}{*}{ Nama Hotel } & \multirow{2}{*}{$\begin{array}{l}\text { Jumlah } \\
\text { Kamar }\end{array}$} & \multicolumn{2}{|c|}{$\begin{array}{c}\text { Harga Kamar } \\
(* 000 \text { Dalam Rp) }\end{array}$} & \multirow[b]{2}{*}{$\%$} & \multicolumn{2}{|c|}{ Occupancy } & \multirow[b]{2}{*}{$\%$} \\
\hline & & & $\begin{array}{c}\text { Low } \\
\text { Season }\end{array}$ & $\begin{array}{c}\text { Cap Go } \\
\text { Meh }\end{array}$ & & $\begin{array}{c}\text { Low } \\
\text { Season }\end{array}$ & $\begin{array}{c}\text { Cap Go } \\
\text { Meh }\end{array}$ & \\
\hline 1 & Hongkong Inn & 30 & 219 & 2.190 & 900 & 16 & 30 & 88 \\
\hline 2 & Rajawali & 42 & 175 & 450 & 157 & 10 & 42 & 320 \\
\hline 3 & Sentosa & 57 & 245 & 278 & 13 & 25 & 57 & 128 \\
\hline 4 & $\begin{array}{c}\text { Sinar } \\
\text { Khatulistiwa }\end{array}$ & 26 & 154 & 206 & 34 & 3 & 26 & 767 \\
\hline
\end{tabular}

Sumber: Data olahan Peneliti

Peningkatan rate kamar yang rendah ternyata berbanding terbalik dengan Hotel Hongkong Inn. Ibu Agnesia, resepsionis, mengatakan saat Cap Go Meh rate kamar bisa mencapai 10 kali lipat harga normal. Rate kamar pada low season Rp219.000 nett, sedangkan saat Cap Go Meh menjadi Rp2.190.000 nett. Pemesanan dapat dilakukan melalui telepon atau datang langsung, atau melalui Online Travel Agent.

Kenaikan rate kamar juga dialami oleh Hotel Rajawali. Hotel ini memiliki jenis kamar standard dan superior, untuk harga standard di low season adalah Rp143.000 nett dan Rp400.000 nett saat Cap Go Meh, superior di Rp175.000 nett dan Rp450.000 nett saat Cap Go Meh. Bapak Slamet,
Resepsionis Hotel yang telah bekerja 4 tahun di hotel ini menyampaikan bahwa perbedaan yang sangat besar dirasakan saat low season dan Cap Go Meh. Di hari biasa, hotel ini sepi pengunjung, hanya sekitar 8-10 kamar terjual dalam 1 hari, namun saat Cap Go Meh, 42 kamar selalu habis. Pemesanan kamar di hotel ini pun masih manual, menggunakan metode telepon atau datang langsung ke hotel.

Pada saat melakukan observasi dan pengumpulan data, peneliti mencoba mengamati ketersediaan akomodasi penginapan di Kota Singkawang saat menjelang Cap Go Meh 2019 dari sebuah Online Travel Agent (OTA) Traveloka.

\section{Pandangan dari Segi Industri Restoran (Rumah Makan) di Kota Singkawang}

Tabel 3.

Wawancara Terhadap Restoran (Rumah Makan)

\begin{tabular}{cccccccc}
\hline & & & \multicolumn{3}{c}{ Jumlah Penjualan } \\
\cline { 4 - 5 } No & Nama Restoran & Nama & Tahun & Low & Cap & \\
/ Rumah Makan & Informan & Berdiri & $\begin{array}{c}\text { Low } \\
\text { Season }\end{array}$ & $/$ Hari & Go & /Hari & \\
\hline
\end{tabular}




\begin{tabular}{ccccccccc}
\hline 1 & $\begin{array}{c}\text { Bakmi Kering } \\
\text { Haji Aman }\end{array}$ & Asmania & 2010 & 300 & Porsi & 600 & Porsi & 100 \\
\hline 2 & Hans Kopitiam & Johan & 2016 & $750 \mathrm{rb}$ & $\mathrm{Rp}$ & $1500 \mathrm{rb}$ & $\mathrm{Rp}$ & 100 \\
\hline 3 & Kwetiau Ashuk & Miau San & 1997 & 20 & $\mathrm{Kg}$ & 40 & $\mathrm{Kg}$ & 100 \\
\hline 4 & MS Kopitiam & Ajan & 2019 & $500 \mathrm{rb}$ & $\mathrm{Rp}$ & $10 \mathrm{jt}$ & $\mathrm{Rp}$ & 1900 \\
\hline
\end{tabular}

Sumber: Data olahan Peneliti

Pandangan dari Industri Agen Perjalanan Sebagai Wadah Wisatawan Dalam Melakukan Perjalanan Wisata ke Perhelatan Budaya Cap Go Meh

Tabel 4.

Rangkuman Wawancara Agent Perjalanan

\begin{tabular}{|c|c|c|c|c|c|c|}
\hline \multirow{2}{*}{ No } & \multirow{2}{*}{$\begin{array}{c}\text { Nama } \\
\text { Agen } \\
\text { Travel }\end{array}$} & \multirow{2}{*}{$\begin{array}{l}\text { Tahun } \\
\text { Berdiri }\end{array}$} & \multirow{2}{*}{$\begin{array}{l}\text { Jenis Paket } \\
\text { Perjalanan }\end{array}$} & \multirow{2}{*}{$\begin{array}{c}\text { Harga }(\text { Pax }) \\
(\text { Dalam Rp) }\end{array}$} & \multicolumn{2}{|c|}{ Jumlah Pax } \\
\hline & & & & & 2018 & 2019 \\
\hline 1 & $\begin{array}{c}\text { Dwidaya } \\
\text { Tour }\end{array}$ & 2015 & $4 \mathrm{D} 3 \mathrm{~N}$ & 7.200 .000 & $43-45$ & $43-45$ \\
\hline 2 & $\begin{array}{l}\text { Sentosa } \\
\text { Tour }\end{array}$ & 2008 & $3 \mathrm{D} 2 \mathrm{~N}$ & $\begin{array}{c}2.000 .000- \\
3.000 .000\end{array}$ & $200-300$ & $200-300$ \\
\hline
\end{tabular}

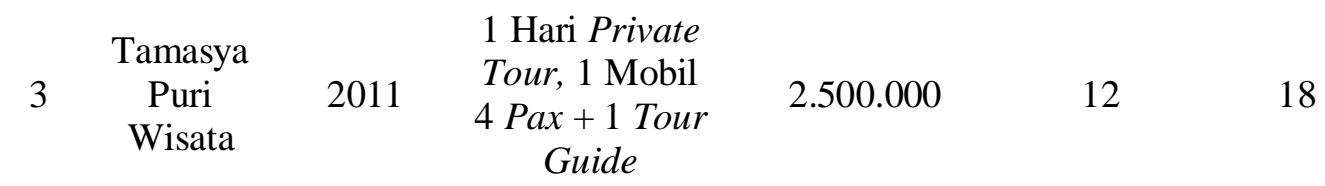

Sumber: Data olahan Peneliti

Pandangan dari segi Industri Rental Mobil Sebagai Sarana Transportasi Wisatawan Saat Cap Go Meh.

Tabel 5.

Statistik Sewa Mobil Pontianak - Singkawang untuk masaLow Season dan

High Season

\begin{tabular}{|c|c|c|c|c|c|c|c|c|c|c|}
\hline \multirow[b]{2}{*}{ No } & \multirow[b]{2}{*}{$\begin{array}{c}\text { Nama } \\
\text { Perusahaan }\end{array}$} & \multirow{2}{*}{$\begin{array}{c}\text { Jumlah } \\
\text { Armada } \\
\text { (Unit) }\end{array}$} & \multicolumn{4}{|c|}{$\begin{array}{c}\text { Harga Penyewaan Mobil } \\
(* 000 \text { Dalam Rupiah) }\end{array}$} & \multicolumn{4}{|c|}{ Jumlah Penyewaan Mobil } \\
\hline & & & $\begin{array}{l}\text { Low } \\
\text { Season }\end{array}$ & & $\begin{array}{c}\text { Cap } \\
\text { Go } \\
\text { Meh }\end{array}$ & & $\begin{array}{l}\text { Low } \\
\text { Season }\end{array}$ & /hari & $\begin{array}{c}\text { Cap } \\
\text { Go } \\
\text { Meh }\end{array}$ & /hari \\
\hline 1 & Palapa Taxi & 55 & 330 & $\begin{array}{l}\text { /org } \\
/ \mathrm{pp}\end{array}$ & 330 & $\begin{array}{l}\text { /org } \\
/ \mathrm{pp}\end{array}$ & 190 & $\operatorname{pax}$ & 266 & pax \\
\hline 2 & $\begin{array}{l}\text { Rizky Jaya } \\
\text { Rental }\end{array}$ & 18 & 800 & $\begin{array}{l}\text { /unit } \\
\text { /hari }\end{array}$ & 1000 & $\begin{array}{c}\text { /unit/ } \\
\text { hari }\end{array}$ & $5-6$ & unit & 17 & unit \\
\hline
\end{tabular}




\begin{tabular}{ccccccccccc} 
& \multirow{2}{*}{$\begin{array}{c}\text { Setiajaya } \\
\text { Rental }\end{array}$} & \pm 30 & 350 & $\begin{array}{c}\text { /unit } \\
\text { /hari }\end{array}$ & 450 & $\begin{array}{c}\text { /unit/ } \\
\text { hari }\end{array}$ & 15 & unit & 30 & unit \\
\hline 4 & $\begin{array}{c}\text { Surya } \\
\text { Transport }\end{array}$ & \pm 24 & 220 & $\begin{array}{c}\text { /org } \\
\text { /pp }\end{array}$ & 220 & $\begin{array}{c}\text { /org } \\
\text { /pp }\end{array}$ & 50 & pax & 65 & pax \\
\hline 5 & $\begin{array}{c}\text { Tritama } \\
\text { Rental }\end{array}$ & \pm 60 & 350 & $\begin{array}{c}\text { /unit } \\
\text { /hari }\end{array}$ & 350 & $\begin{array}{c}\text { /unit/ } \\
\text { hari }\end{array}$ & 25 & unit & 80 & unit \\
\hline
\end{tabular}

Sumber : Data olahan peneliti

\section{Pandangan Retail Store di Sekitar Lokasi Perhelatan Cap Go Meh}

Peneliti mendatangi sebuah retail store yang terletak di Jalan Diponegoro dan mencoba mewawancarai salah satu kasir. Namun tidak banyak informasi yang didapatkan oleh peneliti dikarenakan seluruh karyawan sedang sibuk melayani pembeli yang sedang berbelanja dan mengantri pada line cashier.

Novi, kasir Indomaret, menyampaikan bahwa selama 4 tahun ia bekerja di
Indomaret, ia selalu merasakan peningkatan kunjungan yang signifikan setiap tahunnya saat Imlek. Bahkan pada malam lampion tanggal 17 Februari 2019, Indomaret harus membuka sampai 4 kasir akibat antrian yang panjang dari luar. Tidak hanya pada malam lampion, namun antrian berlanjut hingga tanggal 18 dan 19. Peningkatan kunjungan wisatawan tahun ini menurut Novi lebih ramai daripada tahun sebelumnya yang berdampak pada peningkatan pendapatan Indomaret sekitar 80-100\%. Di hari biasa, pendapatan toko berkisar 50\% dari Cap Go Meh.

\section{Pandangan dari sisi Usaha Pariwisata Mikro: Pedagang Kaki Lima}

Tabel 6

Hasil Wawancara Pedagang Kaki Lima

\begin{tabular}{|c|c|c|c|c|c|c|c|c|}
\hline \multirow[b]{2}{*}{ No } & \multirow[b]{2}{*}{$\begin{array}{c}\text { Nama } \\
\text { Informan }\end{array}$} & \multirow[b]{2}{*}{$\begin{array}{c}\text { Jenis } \\
\text { Dagangan }\end{array}$} & \multirow[b]{2}{*}{$\begin{array}{l}\text { Harga per } \\
\text { Porsi (Rp) }\end{array}$} & \multicolumn{4}{|c|}{ Porsi Terjual } & \multirow[b]{2}{*}{$\%$} \\
\hline & & & & $\begin{array}{c}\text { Low } \\
\text { Season }\end{array}$ & & $\begin{array}{c}\text { Cap } \\
\text { Go } \\
\text { Meh }\end{array}$ & & \\
\hline 1 & Edi & Sosis & 2.000 & 120 & Pcs & 480 & Pcs & 300 \\
\hline 2 & Roni & Es Jeruk & 5.000 & 6,5 & $\mathrm{Kg}$ & 20 & $\mathrm{Kg}$ & 208 \\
\hline 3 & Yanto & Sosis & 3.000 & 225 & Pcs & 960 & Pcs & 327 \\
\hline
\end{tabular}

Sumber : Data Olahan Peneliti

Pandangan dari dari sisi Wisatawan yang berkunjung

Tabel 7

\section{Rangkuman Wawancara Wisatawan}

\begin{tabular}{ccccccc}
\hline \multirow{2}{*}{ No } & \multirow{2}{*}{ Indikator } & \multicolumn{5}{c}{ Nama Wisatawan } \\
\cline { 3 - 6 } & & Andreas & Chici & Febryan & Hendra & Yosafat \\
\hline 1 & Usia & 63 tahun & 24 tahun & 21 tahun & 27 tahun & 23 tahun \\
\hline
\end{tabular}




\begin{tabular}{clccccc}
\hline 2 & Asal & Jakarta & Pontianak & Jakarta & Semarang & Serang \\
\hline 3 & $\begin{array}{l}\text { Jumlah } \\
\text { rombongan }\end{array}$ & 12 & 2 & 3 & 3 & 3 \\
\hline 4 & $\begin{array}{l}\text { Kali } \\
\text { kunjungan }\end{array}$ & 1 & $>=2$ & 1 & 1 & 1 \\
\hline 5 & $\begin{array}{l}\text { Referensi } \\
\text { acara }\end{array}$ & Kerabat & Teman & $\begin{array}{c}\text { Teman } \\
\text { dan } \\
\text { Internet }\end{array}$ & Internet & Teman \\
\hline 6 & $\begin{array}{l}\text { Length of stay } \\
7\end{array}$ & 2 Hari & 2 Hari & 3 Hari & 3 Hari & 3 Hari \\
\hline $\begin{array}{l}\text { Motivasi } \\
\text { tujuan wisata }\end{array}$ & Budaya & $\begin{array}{c}\text { Refreshing, } \\
\text { Budaya }\end{array}$ & Budaya & Budaya & Budaya \\
\hline $\begin{array}{l}\text { Rekomendasi } \\
\text { dan } \\
\text { kemungkinan } \\
\text { kembali }\end{array}$ & Tidak & Ya & Ya & Ya & Ya
\end{tabular}

Sumber : Olahan Data Peneliti

Tabel 8

Pertimbangan dan Penilaian Wisatawan Terhadap Perhelatan Budaya Cap Go Meh Kota Singkawang

\begin{tabular}{|c|c|c|c|}
\hline \multirow[b]{2}{*}{ No } & \multirow[b]{2}{*}{$\begin{array}{c}\text { Nama } \\
\text { Wisatawan }\end{array}$} & \multicolumn{2}{|r|}{ Indikator } \\
\hline & & $\begin{array}{l}\text { Pertimbangan } \\
\text { dalam memilih } \\
\text { destinasi wisata }\end{array}$ & $\begin{array}{c}\text { Penilaian terhadap atraksi wisata Cap } \\
\text { Go Meh Kota Singkawang }\end{array}$ \\
\hline 1 & Andreas & Atraksi & $\begin{array}{c}\text { Atraksi: Sangat Baik } \\
\text { Aksesbilitas: Sangat Baik } \\
\text { Amenitas (Hotel): Baik }\end{array}$ \\
\hline 2 & Chici & Atraksi, Amenitas & $\begin{array}{c}\text { Atraksi: Sangat Baik } \\
\text { Amenitas (Hotel): Kurang Baik } \\
\text { Aksesbilitas: Sangat Baik }\end{array}$ \\
\hline 3 & Febryan & Atraksi, Amenitas & $\begin{array}{c}\text { Atraksi: Sangat Baik } \\
\text { Amenitas (Hotel): Baik } \\
\text { Aksesbilitas: Sangat Baik }\end{array}$ \\
\hline 4 & Hendra & Atraksi, Amenitas & $\begin{array}{l}\text { Amenitas (Hotel): Kurang Baik } \\
\text { Amenitas (Restoran): Sangat Baik } \\
\text { Aksesbilitas: Baik }\end{array}$ \\
\hline 5 & Yosafat & $\begin{array}{c}\text { Atraksi, Amenitas, } \\
\text { Cuaca }\end{array}$ & $\begin{array}{l}\text { Atraksi: Sangat Baik } \\
\text { Aksesbilitas: Baik } \\
\text { Amenitas (Hotel): Baik }\end{array}$ \\
\hline
\end{tabular}

Sumber : Olahan Data Peneliti 
Tabel 9.

Estimasi Spending Money Wisatawan

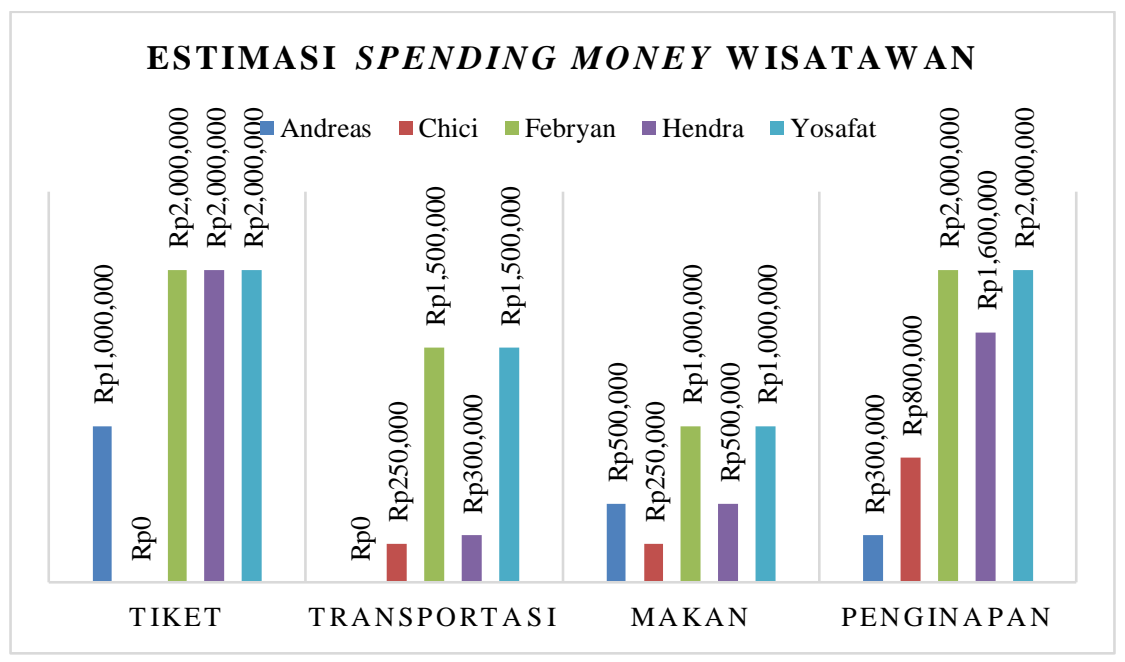

Sumber : Olahan Data Penelitian

Pandangn Perhelatan Budaya Cap Go Meh Menurut Masyarakat Lokal

Tabel 10

Pandangan Masyarakat Lokal Kota Singkawang

\begin{tabular}{|c|c|c|c|c|}
\hline \multirow{2}{*}{ No } & \multirow{2}{*}{ Indikator } & \multicolumn{3}{|c|}{ Nama Informan } \\
\hline & & Jit Lie & Chandri & Aguang \\
\hline 1 & Usia & 27 tahun & 25 tahun & 24 tahun \\
\hline 2 & $\begin{array}{l}\text { Pandangan } \\
\text { terhadap } \\
\text { perhelatan } \\
\text { budaya Cap Go } \\
\text { Meh }\end{array}$ & $\begin{array}{ll}\text { - } & \text { Bangga } \\
\text { - } & \text { Melestarikan } \\
\text { budaya } \\
\text { - } \\
\text { Dikenal } \\
\text { wisatawan }\end{array}$ & $\begin{array}{ll}\text { - } & \text { Bangga } \\
\text { - } & \text { Melestarikan } \\
& \text { budaya } \\
\text { - } & \text { Meningkatkan } \\
\text { pertumbuhan } \\
\text { ekonomi }\end{array}$ & $\begin{array}{l}\text { - Meningkatkan } \\
\text { pertumbuhan } \\
\text { ekonomi }\end{array}$ \\
\hline 3 & $\begin{array}{l}\text { Dampak negatif } \\
\text { yang dirasakan }\end{array}$ & - Sampah & $\begin{array}{l}\text { - Kemacetan lalu } \\
\text { lintas }\end{array}$ & $\begin{array}{l}\text { Pandangan } \\
\text { orang awam } \\
\text { yang tidak } \\
\text { mengerti } \\
\text { budaya } \\
\end{array}$ \\
\hline 4 & $\begin{array}{l}\text { Saran untuk } \\
\text { perkembangan } \\
\text { pariwisata Kota } \\
\text { Singkawang }\end{array}$ & $\begin{array}{l}\text { - Penambahan } \\
\text { tempat } \\
\text { sampah saat } \\
\text { Cap Go Meh }\end{array}$ & 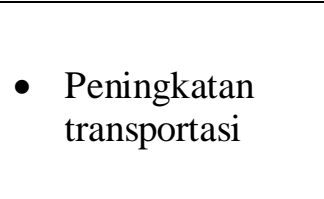 & $\begin{array}{l}\text { - Penambahan } \\
\text { akomodasi } \\
\text { penginapan dan } \\
\text { restoran }\end{array}$ \\
\hline
\end{tabular}


- Pengembangan infrastruktur

- Promosi

Sumber : Olahan Data Peneliti

\section{Dampak Perhelatan Budaya Cap Go Meh Terhadap Kota Singkawang}

Dari hasil observasi peneliti, bahwa dampak yang paling besar terlihat ada pada peningkatan ekonomi Kota Singkawang. Dilihat dari peningkatan pendapatan terhadap usaha pariwisata meliputi akomodasi penginapan (hotel), restoran (rumah makan), agen perjalanan, rental mobil, pedagang kaki lima, dan retail store. Seluruh usaha pariwisata yang diwawancarai mengalami peningkatan pada pendapatan usaha mereka. Hal ini juga berdampak pada pendapatan daerah melalui pajak yang semakin naik dengan naiknya pendapatan pada usaha pariwisata.

Perhelatan budaya ini juga menciptakan lapangan kerja untuk masyarakat lokal sehingga mereka terlibat langsung dengan wisatawan seperti menjadi tour guide, menjual makanan, dsb.

Selain dampak positif, pelaksanaan perhelatan budaya Cap Go Meh ini ternyata juga menimbulkan dampak negatif antara lain:

1.Terhadap lingkungan, yaitu bertambahnya sampah yang dibawa oleh wisatawan.
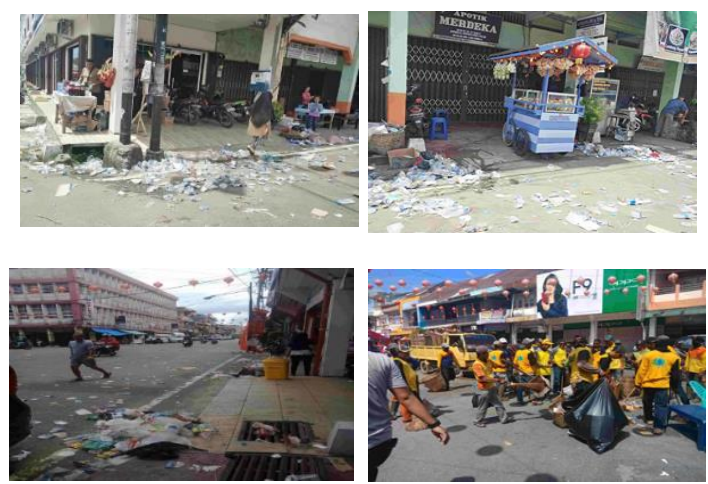

Gambar 2.

Dokumentasi observasi Peneliti di lapangan

2.Beberapa hotel mengalami kenaikan harga dari hari biasa (low season) dan saat Cap Go Meh, seperti Hotel Hongkong Inn yang mengalami kenaikan harga hingga 900\% dari Rp219.000 menjadi Rp2.190.000 atau Hotel Rajawali dengan kenaikan harga 157\% dari Rp175.000 menjadi Rp450.000. Hal ini dari pandangan peneliti kurang baik, dimana kenaikan harga yang terlalu besar ini dapat mengurangi minat kunjungan dari wisatawan untuk berkunjung kembali

\section{Tingkat Kunjungan Wisatawan dan Pendapatan Asli Daerah (PAD) Kota Singkawang}

\section{Tabel 11}

Pendapatan Asli Daerah (PAD) Pariwisata Kota Singkawang

\begin{tabular}{ccccccc}
\hline Uraian & $\mathbf{2 0 1 5}$ & $\mathbf{\%}$ & $\mathbf{2 0 1 6}$ & $\mathbf{\%}$ & $\mathbf{2 0 1 7}$ & $\boldsymbol{\%}$ \\
\hline Hotel & 638.511 .010 & 40,27 & 790.747 .601 & 23,84 & 2.135 .429 .967 & 170,05 \\
\hline Restoran & 1.391 .992 .832 & 55,56 & 2.913 .753 .440 & 109,32 & 4.808 .502 .974 & 65,03 \\
\hline Hiburan & 378.631 .195 & 28,80 & 960.246 .067 & 153,61 & 2.332 .350 .379 & 142,89 \\
\hline Jumlah & $\mathbf{2 . 4 0 9 . 1 3 5 . 0 3 7}$ & $\mathbf{4 6 , 5 4}$ & $\mathbf{4 . 6 6 4 . 7 4 7 . 1 0 8}$ & $\mathbf{9 3 , 6 3}$ & $\mathbf{9 . 2 7 6 . 2 8 3 . 3 2 0}$ & $\mathbf{9 8 , 8 6}$ \\
\hline
\end{tabular}

Sumber : Data olahan Peneliti 


\section{SIMPULAN}

1. Dampak positif paling besar yang ditemukan pada penelitian ini merupakan dampak pada perekonomian Kota Singkawang. Sejumlah usaha pariwisata mengalami peningkatan pendapatan secara signifikan saat perhelatan budaya Cap Go Meh dilaksanakan setiap tahunnya. Usaha pariwisata tersebut meliputi Hotel, Restoran (Rumah Makan), Agen Perjalanan, Sarana Transportasi (Rental Mobil), Pedagang Kaki Lima dan Retail Store.

2. berdampak pada Pendapatan Asli Daerah (PAD) Kota Singkawang yang mengalami peningkatan setiap tahun. Pada tahun 2017, Pendapatan Asli Daerah (PAD) Kota Singkawang mengalami peningkatan $98,86 \%$ dari tahun 2016 atau sebesar 9.276.283.320 dari awalnya 4.664.747.108. Bahkan sampai dengan bulan Juni 2018, target Pendapatan Asli Daerah (PAD) Kota Singkawang telah mencapai Rp8.900.000.000 yang berasal dari pajak hotel, pajak restoran (rumah makan), dan pajak hiburan.

3. Selain dampak positif yang ditimbulkan, ada dampak negatif yang dihasilkan yakni terhadap lingkungan yakni meningkatnya volume sampah yang dibawa oleh wisatawan ke lokasi perhelatan. Dampak lainnya adalah adanya kenaikan harga paket agen perjalanan dan kamar hotel yang terlalu tinggi yang dapat berdampak pada penurunan kunjungan wisatawan di waktu mendatang.

\section{Saran}

1. peningkatan sarana dan prasarana untuk menunjang kebutuhan wisatawan yang diharapkan akan semakin meningkat. Sarana dan prasarana tersebut meliputi penambahan akomodasi penginapan (hotel), restoran (rumah makan), bandar udara, pengembangan sarana transportasi seperti pembangunan jalan tol, pembangunan dan pengembangan infrastruktur serta tata kota.

2. Usaha pariwisata yaitu akomodasi penginapan (hotel) dan agen perjalanan agar terus meningkatkan kualitas dan menjaga keseimbangan harga kamar dan paket perjalanan yang terjangkau dan tidak terlalu tinggi sehingga wisatawan tidak terbebani karena tingginya biaya untuk berwisata. Dengan menjaga kestabilan harga kamar dan paket perjalanan yang terjangkau, maka diharapkan hal ini dapat semakin meningkatkan jumlah kunjungan wisatawan yang akan berkunjung ke Kota Singkawang di masa mendatang

3. Menjaga lingkungan yang tetap bersih dan nyaman dengan tidak membawa dan meninggalkan sampah pada saat melakukan perjalanan wisata di lokasi perhelatan. Hal ini tidak hanya berlaku pada perhelatan budaya Cap Go Meh di Kota Singkawang namun juga di destinasi wisata lainnya untuk menciptakan pariwisata yang berkelanjutan.

\section{DAFTAR PUSTAKA}

$\begin{array}{llrr}\text { Afrizal. } & \text { (2017). } & \text { Metode } & \text { Penelitian } \\ \text { Kualitatif: } & \text { Sebuah } & \text { Upaya } \\ \text { Mendukung } & & \text { Penggunaan }\end{array}$


Penelitian Kualitatif Dalam

Berbagai Disiplin Ilmu. Depok: RajaGrafindo Persada.

Ardianto, Elvinaro. (2011). Metodologi Penelitian untuk Public Relations Kualitatif dan Kuantitatif. Bandung: Simbiosa Rektama Media.

Arjana, I Gusti Bagus. (2016). Geografi Pariwisata dan Ekonomi Kreatif. Depok: RajaGrafindo Persada.

Ahimsa, Putra, dan Tuti Artha, Arwan. (2004). Jejak Masa Lalu: Sejuta Warisan Budaya. Yogyakarta: Kunci Ilmu.

Bungin, Burhan. (2015). Metodologi Penelitian Sosial dan Ekonomi: Format-Format Kuantitatif Dan Kualitatif Untuk Studi Sosiologi, Kebijakan Publik, Komunikasi, Manajemen, dan Pemasaran. Jakarta: Kencana Prenada Media Group.

Muljadi, A. J. (2019). Kepariwisataan dan Perjalanan. Jakarta: PT RajaGrafindo.

Moleong, Lexy J. (2014). Metodologi Penelitian Kualitatif. Bandung: Remaja Rosdakarya.

Pitana, I Gede dan Gayatri, Putu G. (2005). Sosiologi Pariwisata. Yogyakarta: Andi Publisher.

Pitana, I Gede dan Surya Diarta, I Ketut. (2009). Pengantar Ilmu Pariwisata. Yogyakarta: Penerbit Andi.

Poerwanto, Hari. (2005). Orang Cina Khek Dari Singkawang. Depok: Komunitas Bambu.

Rahmawati, Neni Puji Nur, dan Wilis Maryanto. (2004). Sejarah Kota Singkawang. Pontianak: Kementerian Kebudayaan dan Pariwisata.
Setyosari, Punaji. (2016). Metode Penelitian Pendidikan \& Pengembangan. Jakarta: Prenada Media.

Sudaryono. (2017). Metodologi Penelitian. Depok: RajaGrafindo Persada.

Suharsimi, Arikunto. (2016). Prosedur Penelitian: Suatu Pendekatan Praktik. Jakarta: Rineka Cipta.

Suhartanto, Dwi. (2008). Perilaku Konsumen: Tinjauan Aplikasi di Indonesia. Bandung: Guardaya Intimarta.

Sugiarto, dkk. (2015). Metodologi Penelitian Hospitaliti dan Pariwisata. Tangerang: Matana Publishing Utama.

Sugiyono. (2017). Metode Penelitian Bisnis (Pendekatan Kuantitatif, Kualitatif, dan R\&D). Bandung: Alfabeta.

Sunaryo, Bambang. (2013). Kebijakan Pembangunan Destinasi Pariwisata Konsep dan Aplikasinya di Indonesia. Yogyakarta: Gava Media.

Wahab, Salah, dkk. (1992). Pemasaran Pariwisata. Jakarta: Pradnya Paramita.

Yoeti, Oka, dkk. (2015). Pengantar Ilmu Pariwisata. Bandung: Angkasa.

Yoeti, Oka, dkk. (2016). Perencanaan dan Pengembangan Pariwisata. Jakarta: Balai Pustaka. 